\title{
Evaluation of knowledge and attitude of medical interns regarding oral and dental health in Yazd (2016)
}

\author{
Jamshid Ayatollahi ${ }^{1}$, Elham Morovvati ${ }^{2 *}$, Seyed Hossein Shahcheraghi ${ }^{3^{*}}$ \\ 1 Professor, Infectious Diseases Research Center, Shahid Sadoughi Hospital, Shahid Sadoughi University of Medical Sciences, Yazd, Iran \\ 2 General Physician, Shahid Sadoughi University of Medical Sciences, Yazd, Iran \\ 3 Infectious Diseases Research Center, Shahid Sadoughi University of Medical Sciences, Yazd, Iran \\ *Corresponding Author: \\ Dr. Elham Morovvati, General Physician, Shahid Sadoughi University of Medical Sciences, Yazd, Iran. \\ Tel: +98-353-8229200, E-mail: elhammorovvati6@gmail.com \\ Dr. Seyed Hossein Shahcheraghi, Infectious Diseases Research Center, Shahid Sadoughi University of Medical Sciences, Yazd, \\ Iran. \\ Tel: +98-9132531389, E-mail: shahcheraghih@gmail.com
}

Received: August 25, 2019; Accepted: October 02, 2019

\section{Abstract}

The importance of oral health is not covered by anyone. Considering the health of the mouth and teeth for particular reasons is of unique importance. Currently, there is no separate unit in the medical education program of the medical students for oral diseases and their treatment.

The purpose of this study is to investigate the knowledge and practice of medical interns about common oral and dental problems, and to evaluate the presentation of the same subject in the training of medical students and assessment of the organization of an internship in this field. The present study was fieldwork and by collecting questionnaires containing 28 questions from authored papers in recent years and presenting them to interns in 2016 by census and according to age, gender, year of entrance and university of education in medical university Shahid Sadoughi Yazd. Comparing knowledge and attitude of students in different universities showed that the level of knowledge of students in the three universities was the same and there was no significant difference. The lack of knowledge of medical students about oral hygiene and their overall positive attitude towards addressing such a shortage indicates the need to include this topic in the cortical of medical students providing this topic as part of the public health education curriculum.

Keywords: Interns' knowledge, Oral and dental health, Yazd.

\section{INTRODUCTION}

Oral diseases, like diseases of other parts of the body, have been hurting people for years, and humans have always been looking for ways to get rid of them. Failure to comply with oral hygiene causes tooth decay and periodontal diseases, which are the most common diseases and devote a significant portion of their time and expense to families and governments. The mouth is full of numerous bacteria that cause some diseases of the teeth and gums [1].

Some researchers believe that oral infections, especially periodontitis, are closely linked to cardiovascular disease [2-5].
Periodontitis is a chronic infection that begins with the presence of microorganisms and plaque formation [6, 7]. Bacteria in the mouth first form biofilm or plaque, then gingivitis and then periodontitis infection if the oral hygiene is not respected. The association of this disease with bacterial endocarditis is higher in young men who smoke or are injectable [8-11].

Physicians as individuals, who, in addition to dentists, diagnose and sometimes treat certain oral diseases, should naturally have reliable information about these diseases and their treatment [12-14]. Personal health plays an important role in the health, development and empowerment of society. Oral health is one of the important branches of public health that has an important 
impact on the health and quality of life of individuals $[15,16,17]$.

Since it is essential to change people's health habits and behaviors, to assess their current health awareness, this study aimed to assess the level of knowledge of dental practitioners about oral health at Yazd Universities, International and Azad Universities. The feedback of this research on determining the level of awareness of these students is certainly aimed at raising their awareness and improving their attitude towards oral health, which ultimately plays an important role in providing better health education and better services to students.

\section{MATERIALS AND METHODS}

This is a descriptive cross-sectional study with code of ethics Ir.ssu.medicine.rec.1394.236. The fieldwork was done with the census of all interns.

The study population consisted of 111 medical interns of Yazd University of Medical Sciences (77 national universities, 30 international universities, 3 Azad universities) who were designing in 2016.

Data collection tool was a questionnaire prepared by a researcher using reliable sources.

The variables used in this study included 3 dependent variables (knowledge and attitude) and 3 independent variables (age, gender and university of study).

Fortunately, there was no specific administrative problem with the investigation. The only limitation in this study was the occupation of interns in the hospital, which made the study not a concurrent test on the total sample size.

Data were coded and extracted using a questionnaire. Finally, ANOVA test was used to compare the level of students' knowledge in Yazd, Iran.

\section{RESULTS}

In this study, attitude and knowledge of 111 interns of Yazd medical schools were studied. 77 people (69.4\%) from national university, 31 (27.9\%) from international university and $3(2.7 \%)$ from Azad university participated in this study.

Of the 111 interns, 50 (45.0\%) were male and 61 (55.0\%) were female. The age of the study participants was 24 years and no changes were observed.

The minimum score of students' knowledges was 2 and the maximum score was 27 and the mean score of these students was 14.7 with a standard deviation of $4.3(14.7 \pm 4.3)$.

The following table shows the classification of students' attitudes and knowledge scores in three levels of low (less than $50 \%$ ), moderate (between 50 and $75 \%$ ) and high (more than $75 \%$ of correct answers), the frequency and percentage of which are in the three levels as described in Table 1.

According to the table below and Fisher test and $\mathrm{p}$-value = 0.490 , there was no significant difference between the frequency distribution of male and female students' knowledge levels (Table 2).
Table 1: Classification of Students' Attitude and Knowledge Score

\begin{tabular}{|c|c|c|}
\hline Score & Frequency & Percentage \\
\hline Poor & 53 & 47.7 \\
\hline Intermediate & 53 & 47.7 \\
\hline High & 5 & 4.5 \\
\hline
\end{tabular}

Table 2: Frequency Distribution of Students' Knowledge Levels by Gender

\begin{tabular}{|c|c|c|c|}
\hline Score & $\begin{array}{c}\text { Male } \\
\text { N (\%) }\end{array}$ & $\begin{array}{c}\text { Female } \\
\text { N (\%) }\end{array}$ & $\begin{array}{c}\text { Total } \\
\mathbf{N}(\%)\end{array}$ \\
\hline Poor & $26(49.1)$ & $27(50.9)$ & $53(100)$ \\
\hline Intermediate & $21(39.6)$ & $32(60.4)$ & $53(100)$ \\
\hline High & $3(60)$ & $2(40)$ & $5(100)$ \\
\hline \multicolumn{2}{|l}{ N: Number Percent }
\end{tabular}

Also, according to Table 3 , t-test and $p$-value $=0.466$ there was no significant difference between male and female students' knowledge score.

According to the following table and Fisher test and p-value $\leq$ 0.001 there is a significant difference between the frequency distribution of students' knowledge levels in different universities (Table 4).

Table 3: Mean score of students' knowledges based on gender

\begin{tabular}{|c|c|}
\hline Mean \pm SD & Gender \\
\hline $4.69 \pm 14.42$ & Male \\
\hline $4.12 \pm 15.03$ & Female \\
\hline
\end{tabular}

Table 4: Students' knowledge levels based on different universities in Yazd province

\begin{tabular}{|c|c|c|c|c|}
\hline \multirow{2}{*}{ Score } & \multicolumn{3}{|c|}{ University } & $\begin{array}{c}\text { Total } \\
\text { N (\%) }\end{array}$ \\
\cline { 2 - 4 } & Azad & International & National & \\
\hline Poor & $1(1.9)$ & $13(24.5)$ & $39(73.6)$ & $53(100)$ \\
\hline Intermediate & $0(0)$ & $16(30.2)$ & $37(69.8)$ & $53(100)$ \\
\hline High & $2(40)$ & $2(40)$ & $1(20)$ & $5(100)$ \\
\hline Total & $3(2.7)$ & $31(27.9)$ & $77(69.4)$ & $\begin{array}{c}111 \\
(100)\end{array}$ \\
\hline N: Number & $\%$ Percent
\end{tabular}

\section{DISCUSSION}

In the present study, attitudes and knowledge of 111 interns of Yazd University of Medical Sciences (Shahid Sadoughi, Campus International, Yazd Azad University) about common oral diseases were evaluated and their mean score of 28 points related to awareness questions. And attitude was $14.7 \pm 4.3$. There was also a significant difference between the frequency distribution of students' knowledge levels in different universities.

In a descriptive cross-sectional study conducted in Tehran Medical Schools, among 391 interns including interns of Tehran University of Medical Sciences, Shahid Beheshti University of 
Medical Sciences, Tehran and Islamic Azad University of Tehran in 2011, questionnaire information containing questions in Oral health case was obtained. The mean age of the subjects was $25.18 \pm 1.25$ years and the mean score of knowledge in interns was $4.87 \pm 1.73$ out of $15.44 .2 \%$ of the participants were male and the rest were female. Age, sex and duration of internship had no effect on interns' level of knowledge [17].

In another study conducted by the International Division (Kish Campus) of Shiraz University of Medical Sciences, among 159 undergraduate students in medicine (54 cases), dentistry (69 cases) and pharmacy (36 student) in 2011-2012, information a questionnaire containing questions about oral health was obtained through a questionnaire. In this study, the level of knowledge of dental students was higher than the other two groups, and the pharmacy students had better knowledge than the medical students. The results also showed that there was a significant relationship between the level of students' knowledge of oral health and their field of study, duration of university education and diploma placement. However, there was no significant relationship between the level of knowledge of students and their parents' education [18].

A study was conducted in 2012 at Ahvaz Jundishapur University of Medical Sciences in which 80 interns were evaluated. A questionnaire consisting of 18 questions was prepared using other similar research with the opinion of 5 specialists in the field of oral diseases and consisting of three parts. The findings of this study showed that $42.5 \%$ of interns were male and $57.5 \%$ of them were 24 to 26 years old. $90 \%$ of them were not familiar with the field of oral diseases. The mean score of males and females in recognition skills was $3.97 \pm 0.25$ and $3.83 \pm 0.16$, respectively. In treatment performance, mean score of male and female interns were $1.94 \pm 0.17$ and $1.96 \pm 0.13$, respectively. There was no statistically significant difference in treatment performance and skill of oral disease diagnosis in male and female students $(P=0.23)$ and $74 \%$ of the subjects agreed to offer a single oral disease course [19].

In another study, the knowledge and attitude of the third- and sixth-year medical students of Babol University of Medical Sciences about oral hygiene were evaluated in 2013-2014 academic year. To compare 50 third-year and sixth-year dental students of this university and 50 third- and fourth-year engineering students of Babol Anooshirvani University of Technology were selected by simple sampling. Questionnaire was used for data collection. 319 students responded to the questionnaires with a mean age of $21.94 \pm 1.28$ years ranging from 19 to 25 years. The mean and standard deviation of medical students' knowledge scores were $8.02 \pm 3.41$, dental students $15.35 \pm 2.47$ and engineering students $5.73 \pm 2.68$, respectively. $61.7 \%$ of medical students tended to present oral health topics in their academic courses [20].

\section{CONCLUSION}

In the present study in Yazd, the quality of education related to oral diseases was similar in all three universities, and the reports in this study and other similar studies show that the knowledge and attitude of medical students regarding oral health is poor. And requires the provision of a separate unit during the medical course for training.

\section{Acknowledgement}

The authors wish to thank the staff of Infectious Diseases Research Center of Shahid Sadoughi University of Medical Sciences, Yazd.

\section{Conflict of Interest}

We declare that we have no conflict of interest.

\section{Financial Support}

None declared.

\section{REFERENCES}

1. Thomas NJ, Middleton PF, Crowther CA. Oral and dental health care practices in pregnant women in Australia: a postnatal survey. BMC pregnancy and childbirth. 2008;8(1):13.

2. Byrd MG, Quinonez RB, Lipp K, Chuang A, Phillips C, Weintraub JA. Translating prenatal oral health clinical standards into dental education: results and policy implications. Journal of Public Health Dentistry.

3. Pellegrino A, Vendetti T, Jackson T, Zwetchkenbaum S. Oral Health Concerns and Connections to Mental Health among Rhode Island High School Students, 2017. Rhode Island medical journal (2013). 2018;101(8):56.

4. Su Y, Behar-Horenstein LS. Assessment of Psychometric Properties of an Oral Health Care Measure of Cultural Competence Among Dental Students Using Rasch Partial Credit Model. Journal of dental education. 2018;82(10):1105-14.

5. Yadav K, Solanki J, Dileep C, Adyanthaya B, Mishra P, Yadav O. Association between different blood groups, depression and oral health status of dental students. Clujul Medical. 2018;91(3):317.

6. Fejerskov $\mathrm{O}$. Changing paradigms in concepts on dental caries: consequences for oral health care. Caries research. 2004;38(3):182-91.

7. Kleinberg I. A mixed-bacteria ecological approach to understanding the role of the oral bacteria in dental caries causation: an alternative to Streptococcus mutans and the specific-plaque hypothesis. Critical Reviews in Oral Biology \& Medicine. 2002;13(2):108-25.

8. Ainamo J, Bay I. Problems and proposals for recording gingivitis and plaque. International dental journal. 1975;25(4):229-35.

9. Ebbeling S, Adam L, Meldrum A, Rich A, McLean A, Aitken W. Oral Health and Dental Students' Perceptions of Their Clinical Learning Environment: A Focus Group Study. Journal of dental education. 2018;82(10):1036-42.

10. Zhou $Y$, Chen D, Zhi Q, Tao $Y$, Wang X, Feng $X$, et al. The Prevalence and Associated Risk Indicators of Dental Fluorosis in China: Findings from the 4th National Oral Health Survey. The Chinese journal of dental research: the official journal of the Scientific Section of the Chinese Stomatological Association (CSA). 2018;21(3):205-11.

11. Enshaei Z, Feizi A, Saied-Moallemi Z. Oral health behaviours and oral health-related dietary behaviours: The interrelationship and determinants by latent class analysis. Community dental health. 2018.

12. Parat K, Radić M, Borić K, Perković D, Biočina Lukenda D, Martinović Kaliterna D. Association of low socioeconomic status 
and physician assessment of disease severity with oral healthrelated quality of life in patients with systemic sclerosis: a pilot study from Croatia, a country in transition. Journal of International Medical Research. 2018:0300060518791089.

13. Patel R, Witton R, Potterton R, Smith W, Kaimi I. Dental Public Health in Action: Understanding oral health care needs and oral health-related quality of life in vulnerable adults in Plymouth. Community dental health. 2018.

14. Abbott B, Zybutz C, Scott KM, Eberhard J, Widmer R. A review of the hours dedicated to oral health education in medical programmes across Australia. Internal medicine journal. 2018;48(9):1035-40.

15. Estes KR, Callanan D, Rai N, Plunkett K, Brunson D, Tiwari T. Evaluation of an Interprofessional Oral Health Assessment Activity in Advanced Practice Nursing Education. Journal of dental education. 2018;82(10):1084-90.

16. Modell S, Citrin T, Kardia S, editors. Laying Anchor: Inserting Precision Health into a Public Health Genetics Policy Course. Healthcare; 2018: Multidisciplinary Digital Publishing Institute.

17. Nassiri M, Karamali M. Interns' knowledge about pediatrics teeth and mouth health in Tehran educational hospitals, Iran, 2011. Journal of Mazandaran University of Medical Sciences. 2014;23(110):226-30. [In Persian]

18. Habibi A, Bagheri K, Hajizadeh P, Tarjan A, Khosravi E. Oral health knowledge among pre-clinical students of International Branch of Shiraz University of Medical Sciences. Journal of Dental Medicine. 2015;27(4):29-35. [In Persian]

19. Shooryabi M, Razawi Satvati S, Mansoori B, Nemati Zive A, Haghnegahdar S, Robati M. Medical students' clinical skill rate in diagnosis of oral mucosal disease at Ahvaz Jundishapur University of Medical Sciences. Res Dent Sci. 2013;10(3):205-10. [In Persian]

20. Babaee N, Jahanian I, Bijani A, Samadi J. Needs Assessment on Inserting Oral Health Topics in General Medicine Educational Curriculum. Babol Univ Med Sci. 2013; 1 (2): 19-26. [In Persian] 